\title{
Laparoscopic evaluation of pelvis in infertile women with previous genital and extra genital tuberculosis
}

\author{
Kiran Aggarwal*, Rashmi Medha \\ Department of Obstetrics and Gynecology, Lady Hardinge Medical College, New Delhi, India \\ Received: 07 April 2017 \\ Accepted: 17 April 2017 \\ *Correspondence: \\ Dr. Kiran Aggarwal, \\ E-mail: dr_kiranaggarwal@hotmail.com \\ Copyright: (c) the author(s), publisher and licensee Medip Academy. This is an open-access article distributed under \\ the terms of the Creative Commons Attribution Non-Commercial License, which permits unrestricted non-commercial \\ use, distribution, and reproduction in any medium, provided the original work is properly cited.
}

\begin{abstract}
Background: Genital tract tuberculosis causes infertility is a known fact but does past extra genital tuberculosis which had been treated also affects genital tract silently and causes significant genital involvement and infertility. The aim of this study was to study laparoscopic evaluation of pelvis in infertility patients with past history of treated genital and extra genital tuberculosis.

Methods: 40 infertile patients with past history of treated genital (11) and extra genital (29) tuberculosis were included in the study. The study was conducted in a tertiary level hospital for one and a half years. After initial evaluation and work up and ruling out any active infection patients were posted for laparoscopic evaluation and proceed.

Results: Most common site of extra genital tuberculosis was pulmonary tuberculosis in 52. 50\%. Primary infertility was more common in both the groups, around $72 \%$. Menstrual patterns were significantly different. $45.45 \%$ in women in group with genital tuberculosis presented with hypo menorrhoea as compared to only $13.79 \%$ in women with extra genital tuberculosis. Laparoscopic findings showed evidence of squealae of past tubercular infection like peritubular adhesions, omental adhesions, fibrosed distorted tubes, tubo-ovarian masses, hydrosalpinx, difficulty to visualise the tubes and ovaries and various combinations of these in most of the cases in women with genital tuberculosis $(72.73 \%)$ of cases. These findings were seen in $37.93 \%$ of women with past extra genital tuberculosis.

Conclusions: Genital tract may silently get invaded in primary extra genital tuberculosis. It is important for young girls affected by this to be treated diligently which might reverse the changes in time.
\end{abstract}

Keywords: Extra genital tuberculosis, Infertility, Laparoscopic evaluation

\section{INTRODUCTION}

Tuberculosis as a cause of infertility is a major problem in the developing countries.

Genital tuberculosis (TB) in females is found in 0.75 to $1 \%$ of gynecological admissions in India and occurs in about $10 \%$ cases of pulmonary tuberculosis. ${ }^{1}$ Genital TB occurs mostly secondary to pulmonary tuberculosis, commonly by the haematogenous route. The fallopian tubes are affected in almost $100 \%$ of the cases followed by the endometrium in $50 \%$, ovaries in $20 \%$, cervix in $5 \%$ and vagina and vulva in $<1 \%$. $^{2,3}$ Incidence of female genital tuberculosis has been reported to be $19 \%$ in India in infertile patients. ${ }^{4}$ Female genital tuberculosis (FGTB) causes significant morbidity. It causes infertility due to fibrosis and scarring occurring as a part of healing. These long term changes are not reversible even after treatment. F GTB occurs in the most economically productive age (15-54 years) causing infertility in $44-74 \%$ of the women affected. ${ }^{5,7}$ It is usually difficult to diagnose because it is a silent invader of genital tract, has varied presentations and is paucibacillary in nature. Genital tract affection by tuberculosis is a well-documented fact but in number of cases extra genital tuberculosis also affects the gential 
tract silently and seems to be an important cause of infertility.

How much involvement of genital tract is there in patients of extra genital tuberculosis to the extent that they cause infertility is not known.

This study was planned on observing that asymptomatic patients undergoing laparoscopic evaluation for infertility especially with blocked tubes on hysterosalpingogram or with unexplained infertility had significant findings on laparoscopy of old healed infection in patients with past history of treated extra genital tuberculosis. Not many studies are there addressing this correlation

\section{METHODS}

This was a cross sectional observational study conducted in a tertiary level hospital in India for one and a half years. 40 consecutive patients undergoing diagnostic laparoscopic evaluation for infertility with past history of treated extra genital (29 patients) and genital tuberculosis (11 patients) were included in the study. Only those patients with documented at least 6 months of ATT were included in the study.

Patients with any systemic or local features of active infection or active genital/extra genital tuberculosis were excluded. Laparoscopic evaluation of pelvis was being done in these patients for tubal blockage or as a part of workup for unexplained infertility. All patients had a detailed history taking, examination and were investigated for infertility. Apart from routine investigations all patients had Husbands' semen analysis, premenstrual endometrial sampling, ultrasonography of the pelvis, post menstrual hysterosalpingogram and then were posted for laparoscopic evaluation and proceed. 29 patients of extra genital tuberculosis and 11 patients of genital tuberculosis were included in the study.

Laparoscopic examination was done under general anaesthesia and pelvic and abdominal findings were systematically recorded. Omental and peritubular adhesions were noted and mentioned. Status of uterus, visibility and condition of tubes, ovaries and pelvis was recorded. Presence of tubo-ovarian masses and hydorsalpinges were noted. Chromopertubation was done with methylene blue and patency of the tube was recorded. According to the need further operative procedure like adhesiolysis, fimbrioplasty etc. were carried out. The findings in both the groups were recorded and compared.

The data were collected and computed using SPSS software. The continuous variables were shown as means \pm SD and the categorical variables shown as percentages. The Student $\mathrm{t}$ test and $\chi^{2}$ were used to compare means and proportions, respectively. A $p$ value of $<0.05$ was considered statistically significant.

\section{RESULTS}

Most of the patients were young in the age group of 2030 years $(70 \%)$. $52.50 \%$ patients were between $25-30$ years of age $30 \%$ patients were beyond 30 years with varied intervals of infertility.

Table 1: Distribution of cases according to age.

\begin{tabular}{|lll|}
\hline Age (in years) & $\mathbf{N}$ & $\%$ \\
\hline $20-25$ & 7 & 17.50 \\
\hline $25-30$ & 21 & 52.50 \\
\hline $30-35$ & 8 & 20.00 \\
\hline $35-40$ & 4 & 10.00 \\
\hline Total & $\mathbf{4 0}$ & $\mathbf{1 0 0}$ \\
\hline
\end{tabular}

Table 2: Distribution of cases according to the type of tuberculosis.

\begin{tabular}{|lll|}
\hline History of T'B & N & $\%$ \\
\hline Pulmonary & 21 & 52.50 \\
\hline Genital & 8 & 20.00 \\
\hline Pott's Spine & 2 & 5.00 \\
\hline Abdominal & 4 & 10.00 \\
\hline TB Lymphadenitis & 1 & 2.50 \\
\hline Pulmonary+Genital & 2 & 5.00 \\
\hline Pulmonary+TB Lymphadenitis & 1 & 2.50 \\
\hline Pulmonary+Genital+abdominal & 1 & 2.50 \\
\hline Total & $\mathbf{4 0}$ & $\mathbf{1 0 0}$ \\
\hline
\end{tabular}

Pulmonary tuberculosis was the most common extra genital tuberculosis (52.50\%). However abdominal Koch's, Pott's spine and tubercular lymphadenitis cases were also there. Genital tuberculosis was seen in $20 \%$ alone and when combination with others was included it was seen in $27.5 \%$.

Most of the patients were of primary infertility in both the groups, around $72 \%$. Menstrual patterns were significantly different in the two groups. $45.45 \%$ in women in group with genital tuberculosis presented with hypo menorrhoea as compared to only $13.79 \%$ in women with extra genital tuberculosis. There were no cases of granulomatous endometritis as no cases with active infection were taken. Tubal blockages were comparable in both the groups on hysterosalpingography.

Laparoscopic findings showed evidence of squealae of chronic tubercular infection like peritubular adhesions, omental adhesions, fibrosed distorted tubes, tubo-ovarian masses, hydrosalpinx, difficulty to visualise the tubes and ovaries and various combinations of these in most of the cases in women with genital tuberculosis $(72.73 \%)$ of cases. These findings were seen in $37.93 \%$ of women with past extra genital tuberculosis.

On chromopertubation bilateral blocked tubes were present in $63.63 \%$ of women with past genital tuberculosis and in $20.68 \%$ of women with extra genital 
tuberculosis. Bilateral normal spill was significantly higher in women with extra genital tuberculosis $62.06 \%$ as compared to women with genital tuberculosis $(18.18 \%)$.

Table 3: Comparison of different parameters between past genital and extra genital tuberculosis.

\begin{tabular}{|c|c|c|c|}
\hline & H/O Genital T.B. $(\mathrm{N}=11)$ & H/O Extragenital T.B. $(\mathrm{N}=29)$ & P-Value \\
\hline \multicolumn{4}{|l|}{ Type of infertility } \\
\hline Primary infertility (29) & $8(72.73 \%)$ & $21(72.41 \%)$ & \multirow{2}{*}{0.492} \\
\hline Secondary infertility (11) & $3(27.27 \%)$ & $8(27.59 \%)$ & \\
\hline \multicolumn{4}{|l|}{ Menstrual pattern } \\
\hline Normal (31) & $6(54.55 \%)$ & $25(86.21 \%)$ & \multirow{2}{*}{0.016} \\
\hline Abnormal (hypomenorrhoea) (9) & $5(45.45 \%)$ & $4(13.79 \%)$ & \\
\hline \multicolumn{4}{|l|}{ USG (pelvis) findings } \\
\hline Normal (31) & $8(72.23 \%)$ & $23(79.31 \%)$ & \multirow{2}{*}{0.328} \\
\hline TO mass+hydrosalpinx (9) & $3(27.27 \%)$ & $6(20.69 \%)$ & \\
\hline \multicolumn{4}{|l|}{ Pre menstrual EB } \\
\hline Secretory (38) & $11(100 \%)$ & $27(93.1 \%)$ & \multirow{2}{*}{0.186} \\
\hline Proliferative (2) & 0 & $2(6.9 \%)$ & \\
\hline \multicolumn{4}{|l|}{ HSG } \\
\hline Normal (2) & $1(9.09 \%)$ & $1(3.45 \%)$ & 0.232 \\
\hline U/L Block (12) & $4(36.36 \%)$ & $8(27.59 \%)$ & 0.294 \\
\hline B/L Block (26) & $6(54.55 \%)$ & $20(68.97 \%)$ & 0.197 \\
\hline
\end{tabular}

Table 4: Comparison of, laparoscopic findings between cases with past genital and extra genital tuberculosis.

\begin{tabular}{|c|c|c|c|}
\hline & $\begin{array}{l}\text { H/O Genital T.B. } \\
(\mathrm{N}=11)\end{array}$ & $\begin{array}{l}\text { H/O Extragenital } \\
\text { T.B. }(\mathrm{N}=29)\end{array}$ & $\begin{array}{l}\text { P- } \\
\text { Value }\end{array}$ \\
\hline \multicolumn{4}{|l|}{ Laparoscopic Findings } \\
\hline Normal & $3(27.27 \%)$ & $18(62.06 \%)$ & 0.099 \\
\hline $\begin{array}{l}\text { Peritubular adhesions, omental adhesions, distorted fibrosed } \\
\text { tubes TO mass, hydrosalpinx and various combinations of them }\end{array}$ & $8(72.73 \%)$ & $11(37.93 \%)$ & 0.340 \\
\hline Chromopertubation & $\mathbf{N}$ & $\%$ & \\
\hline $\mathrm{B} / \mathrm{L}$ Blocked tubes & $7(63.63 \%)$ & $6(20.68 \%)$ & 0.06 \\
\hline $\mathrm{U} / \mathrm{L}$ spill & $2(18.18 \%)$ & $5(17.24 \%)$ & 0.34 \\
\hline B/L SPILL & $2(18.18 \%)$ & $18(62.06 \%)$ & 0.03 \\
\hline
\end{tabular}

\section{DISCUSSION}

Tuberculosis is quiet common in the Indian population and causes infertility. Incidence of female genital tuberculosis is $48.5 \%$ with tubal factor infertility. ${ }^{6}$

Patients who had extra genital Tuberculosis and were treated are also there presenting with infertility. It is known that genital tuberculosis normally manifests secondary to an extra genital site mostly primary focus being pulmonary tuberculosis and the spread is haematogenous.

The genital tract gets invaded silently in these varied extra genital sites of tuberculosis and the patient may not be aware of it. This correlation is not very clear. In the scenario of acute primary illness slight changes in menstrual pattern or decrease flow may not have been noticed at that time. In this study we had selected cases with infertility as a complaint without any evidence of any acute infection. They had been treated in the past for both genital and extragenital tuberculosis. These patients were undergoing laparoscopic evaluation for tubal factor and unexplained infertility mainly. In present study $72.73 \%$ of patients with past h/o genital and a significant $37.93 \%$ of women with extra genital tuberculosis on laparoscopic evaluation had shown evidence of past healed chronic tubercular infection. Omental and peritubular adhesions, distorted thickened tubes, shaggy surface of uterus and tubes, presence of tuboovarian masses and hydrosalpinx and a combination of these were important findings.

A study by Sharma et al. in 2016 reported that laparoscopic findings in fallopian tubes in female genital tuberculosis included hydrosalpinx, pyosalpinx, beaded tubes, unilateral or bilateral tubal blockage before and after ATT. The study concluded that ATT improves findings in female genital tuberculosis with infertility but 
advanced fibrotic lesions do not improve with ATT. Involvement of genital tract in tuberculosis elsewhere apart from the genital system is not clear. $13 \%$ genital tract involvement was seen in cases of pulmonary tuberculosis in a study titled 'Genital manifestation of pulmonary tuberculosis'. ${ }^{8}$ Menstrual abnormalities were reported in $66 \%$ of women in patients of pulmonary tuberculosis and $76 \%$ of women with menstrual abnormalities were reported to resume normal menstrual cycles after treatment. ${ }^{9}$ The study had showed that menstrual changes occurring in cases of extra genital tuberculosis were reversible. It is important to note that primary tuberculosis in young females especially should be treated carefully and the patients and family should be counselled regarding the possibility of genital tract involvement.

\section{CONCLUSION}

Genital tract may silently get invaded in primary extra genital tuberculosis. It is important for young girls affected by this to be treated diligently which might reverse the changes in time. Possibility to be treated diligently and timely of genital tract involvement and omit in time subsequent infertility should be explained. Larger studies need to be done in future addressing this issue.

Funding: No funding sources

Conflict of interest: None declared

Ethical approval: The study was approved by the Institutional Ethics Committee

\section{REFERENCES}

1. Arora R, Rajaram P, Oumachigui A, Arora VK. Prospective analysis of short course chemotherapy in female genital tuberculosis. Int J Gynecol Obstet. 1992;38:311-4.

2. Varma TR. Genital tuberculosis and subsequent fertility. Int J Gynaecol Obstet. 1991;35:1-11.

3. Bobhate SK, Kedar SP, Kherdekar M, Kher AI, Grover S. Female genital tract tuberculosis: A pathological appraisal. J Obstet Gynaecol India. 1986;36:676-80.

4. Kulshrestha V, Kriplane A, Agarwal N, Singh UB, Rana T. Genital tuberculosis among infertile women and fertility outcome after antitubercular therapy. Int J Gynecol Obstet. 2011;113(3):229-34.

5. Bhanothu V, Theophilus J, Rozati R, Srikanth D, Vijayalaxmi B, Banoth B. Comparative investigation of female genital tuberculosis gene polymorphism. Int J Curr Res. 2012;4(01):034-40.

6. Singh N, Sumana G, Mittal S. Genital tuberculosis: a leading cause for infertility in women seeking assisted conception in North India. Arch Gynecol Obstet. 2008;278:325-7.

7. Sharma JB, Sneha J, Singh UB, Kumar S, Roy KK, Singh N, et al. Comparative study of laparoscopic abdominopelvic and fallopian tube findings before and after antitubercular therapy in female genital tuberculosis with infertility. J Minim Invasive Gynecol. 2016;23(2):215-22.

8. Tripathy SN. Genital manifestation of pulmonary tuberculosis. Int J Gynaecol Obstet. 1981;19:319-26.

9. Hassan WA, Darwish AM. Impact of pulmonary tuberculosis on menstrual pattern and fertility. Clin Respir J. 2010;4:157-61.

Cite this article as: Aggarwal K, Medha R.

Laparoscopic evaluation of pelvis in infertile women with previous genital and extra genital tuberculosis.

Int J Reprod Contracept Obstet Gynecol 2017;6:2056-9. 